Orbis Tertius, vol. XXIV, $\mathrm{n}^{\circ}$ 30, e130, noviembre 2019-abril 2020. ISSN 1851-7811

Universidad Nacional de La Plata

Facultad de Humanidades y Ciencias de la Educación

Centro de Estudios de Teoría y Crítica Literaria

\title{
La revista Rumbo: un eslabón en la unidad de los intelectuales "por la defensa de la cultura" (Buenos Aires, 1935) ${ }^{1}$
}

Rumbo Magazine: a Link in the Union of "Culture defense" Intelectuals (Buenos Aires, 1935)

Magali Andrea Devés

Instituto Ravignani-Universidad de Buenos Aires, Argentina

magalideves@yahoo.com.ar

\section{Resumen:}

Este artículo tiene por objetivo recuperar y analizar una revista escasamente conocida en la trama de las publicaciones antifascistas de Buenos Aires: Rumbo. A pesar de su efímera existencia - se publicaron tres números entre septiembre y noviembre de 1935- el estudio de esta publicación se justifica pues ilumina un momento transicional de la cultura de las izquierdas, comprendido entre el período "clase contra clase" y los Frentes Populares y, al mismo tiempo, constituye un antecedente de los órganos de la Agrupación de Intelectuales, Artistas, Periodistas y Escritores (AIAPE). En ese marco, las páginas de Rumbo dieron cabida a diversos debates estético-politicos con el propósito de llamar a la organización de los intelectuales en su lucha en contra de los fascismos.

Palabras Clave: Rumbo, intelectuales, Publicaciones antifascistas, AIAPE.

\section{Abstract:}

This article aims to recover and analyze a magazine that is poorly known in the network of anti-fascist publications in Buenos Aires: Rumbo. Despite its ephemeral existence - three issues were published between September and November 1935 - the study of this publication exemplifies a transitional moment of the left's culture, between the "class against class" period and the Popular Fronts. At the same time, Rumbo constitutes an antecedent of the official organs of the Agrupación de Intelectuales, Artistas, Periodistas y Escritores (AIAPE). In this context, the pages of this magazine boosted different aesthetic-political debates with the purpose of organizing intellectuals in their fight against fascism.

KeYWORDS: Rumbo, intellectuals, Anti-fascist publications, AIAPE.

\section{INTRODUCCIÓN}

Bajo la dirección del escritor Álvaro Yunque (seudónimo de Arístides Gandolfi Herrero), en septiembre de 1935 aparecía Rumbo en las calles de Buenos Aires. Esta nueva revista que se sumaba a una red de publicaciones antifascistas confirmaba con su presencia la politización de la cultura en un período signado por el ascenso de Hitler al poder y la consecuente internacionalización del par opuesto "fascismo-antifascismo". Asimismo, Rumbo se hacía eco de la reactualización de los sentidos del término intelectual que se habían instalado a partir del affaire Dreyfus con la celebérrima intervención de Émile Zola ("Yo acuso") y sus posteriores protestas (Dosse, 2007, pp.60-80), pues, como señaló Enzo Traverso, aquella batalla que enfrentó a los intelectuales en dos bandos que representaron el nacionalismo contra el universalismo, el antisemitismo contra la igualdad y el militarismo contra la república, se profundizó después de la Primera Guerra Mundial, cuando al lado de los intelectuales que se movilizaron para defender la democracia, hubo otros que trabajaron para abatirla (2003, p.54). En efecto, tal como lo anticipaba el nombre de la revista, y como se deduce de los contenidos de los tres números, uno de sus principales propósitos radicaba en fomentar el debate sobre el compromiso de los escritores y de los artistas como una premisa ineludible para guiar su "rumbo" y organizar la lucha antifascista desde el ámbito de la cultura.

El presente artículo tiene por objetivo recuperar y analizar esta publicación, escasamente conocida. Su estudio se justifica porque a pesar de su efímera existencia -se publicaron tres números entre septiembre y noviembre de 1935- Rumbo ilumina un momento transicional de la cultura de las izquierdas, comprendido 
entre el período "clase contra clase" y el llamado a la constitución de Frentes Únicos y Populares. Al mismo tiempo, Rumbo emerge como un antecedente de los órganos oficiales de la Agrupación de los Intelectuales, Artistas, Periodistas y Escritores (AIAPE): Unidad (1936-1938) y Nueva Gaceta (1941-1943). En tanto los integrantes de la AIAPE aún no contaban con sus propias publicaciones hicieron oír su voz a través de Rumbo, una revista que cedió su espacio para albergar sus protestas intelectuales, colaboraciones e incentivó la afiliación a la AIAPE. Vale aclarar que muchos de sus integrantes formaban parte del colectivo editor de Rumbo. De esta manera, esta efímera publicación, que apeló a una serie de debates estético-políticos como fundamento para luchar en contra de los fascismos y a un discurso antifascista de orientación comunista que propiciaba la defensa de la cultura sin olvidar la utopía revolucionaria, se constituyó como un terreno fértil para organizar la lucha de los intelectuales en la arena cultural. Por otra parte, en esta publicación es posible observar también el esfuerzo por establecer redes intelectuales entre el universo antifascista francés y el Río de la Plata como sostén para la configuración de un movimiento antifascista local.

\section{LA PROTESTA COMO FUNDAMENTO PARA LA ORGANIZACIÓN INTELECTUAL}

Con el auspicio de Publicaciones Atlas, ${ }^{2}$ entre septiembre y noviembre de 1935 se imprimieron tres números de la revista Rumbo. Con un promedio de dieciocho páginas, un tamaño que no llega a ser tabloide y un módico precio de 10 centavos, en sus páginas se encuentra una variada cantidad de notas de diferentes extensiones, poesías, encuestas e ilustraciones, que revelan el afán por alcanzar a un público amplio y, más específicamente, el anhelo por lograr un vínculo entre los intelectuales y los trabajadores. Dentro del universo de las publicaciones de izquierdas, Rumbo convive con una red de revistas conformada por Claridad. Tribuna del pensamiento izquierdista, Nervio. Critica - artes - letras, Actualidad artistica, económica, social, Izquierda. Acción y Critica Socialista, Nueva Revista, Metrópolis de los escriben para decir algo y Símbolo, entre tantas otras, que comparten muchos de sus colaboradores. En efecto, en Rumbo, además del ya mencionado Yunque (director de la revista), aparecen también, por ejemplo, los nombres de César Tiempo, Emilio Novas, Nicolás Olivari, Nydia Lamarque, Liborio Justo, Juan Lazarte, Roberto Mariani, Alfredo Varela, asiduos colaboradores de las otras publicaciones mencionadas.

Como se advierte, lejos (y definitivamente) había quedado la divisoria de aguas - matizada con el tiempo por la crítica literaria- entre "los de Boedo" y "los de Florida", pues ahora muchos de aquellos nombres "enfrentados" en distintas revistas de los años veinte (Los Pensadores y Martín Fierro) se reunían en un mismo colectivo agrupados por la urgencia de los tiempos. Estas confluencias tuvieron sus antecedentes en otros periódicos, como Argentina (1930-1931) y, más tarde, en Contra. La revista de los franco-tiradores (1933). Concretamente, como señaló Martín Greco, Argentina, dirigida por el escritor y crítico de arte Cayetano Córdova Iturburu, marca la transición entre la década del veinte y la del treinta, puesto que en cada uno de sus números y a través de los debates sobre la función social del arte es posible percibir una progresiva radicalización de su discurso. En palabras del autor: "su rápida evolución expresa la aceleración de los tiempos del compromiso ideológico y sintetiza la conversión de muchos intelectuales, entre ellos el propio Córdova Iturburu, que en pocos meses pasan de defender una revolución puramente estética a combatir por una revolución política de marcado acento antiburgués. Argentina es un periódico en crisis en un momento de crisis" (Greco, 2015, p.217). Pocos años después, esta transformación se profundizaría, como se anticipó, en una nueva publicación: Contra. La revista de los franco tiradores (1933), dirigida por Raúl González Tuñón e influenciada por la estrategia "clase contra clase", impulsada por la Internacional Comunista, en la cual se ensayó la articulación entre vanguardia estética y la vanguardia política (Saítta, 2005, pp.13-33).

Estas tomas de posición estético-ideológicas expresaban, sin dudas, una polarización política que fragmentó a la opinión pública más allá de las fronteras de Europa a partir del ascenso de Hitler al poder y que animó la emergencia de un movimiento antifascista a nivel local producto de la construcción y promoción de dos representaciones que se arraigaron con una fuerza persistente: la "amenaza nazifascista" y el "fascismo 
criollo" (Bisso, 2000; 2007). Ambas imágenes eran muy efectivas gracias al clima abierto por el golpe cívicomilitar del 6 de septiembre de 1930, que inauguró aquella década "infame" caracterizada por un ciclo de clara predominancia de la derecha en el poder, en un primer momento bajo un gobierno con planteos de tipo corporativistas como el de José Félix Uriburu (1930-1932) y luego a través de la política fraudulenta y represiva del gobierno conservador de Agustín P. Justo (1932-1938) continuada, tras el breve interregno de Roberto Ortiz (1938-1940), por Ramón Castillo (1940-1943). Inclusive, estas ideas se reactualizaron posteriormente en torno a la figura de Juan Domingo Perón bajo el sintagma de "naziperonismo" (Nallim 2006).

En este contexto, en las páginas de Rumbo se advierte una radicalización estético-ideológica de las propuestas impulsadas por experiencias anteriores como Argentina y Contra y en contraposición a la proclamada "neutralidad" de los llamados "artepuristas". Como manifiesta el colectivo en su presentación:

RUMBO es una publicación artística. Pero es una publicación artística de este siglo y de este año. Y el arte, hoy, no se entiende como antes de la guerra mundial: 1914 trastocó muchos conceptos. La lucha social se ha agudizado y polariza con violencia a los hombres. El artista puro, tipo principios del siglo XX, ya no existe. En los que así se proclaman basta rozar el brillante barniz para que aparezca de inmediato el hombre de partido y de clase [...] Para estos hombres que se abroquelan en su pureza artística y rehúyen el contacto multitudinario, el arte que se llama social, o tendencioso, o de izquierda, o revolucionario, o proletario, o humanizado, por venir "contaminado" de ideas; no es arte. Pero ellos no dudarían en afirmar que las construcciones góticas de la Edad Media o el Romancero español, “contaminados” por las ideas de la cristiandad, son arte. ¿Por qué es arte aquel arte ideológico del pasado y no lo es éste de hoy, vertebrado por las ideas de ahora? [...] Saber adónde se va, o sea, tener rumbo, para los profesionales del estetismo, es ser sectario. Pero RUMBO tiene rumbo (Sin firma, 1935, p.1).

De esta manera, en su doble acepción, material e ideológica, el mensaje de Rumbo se afirmaba por medio de la tinta roja con que imprimía su nombre en la portada y en una importante cantidad de ilustraciones, viñetas y caricaturas que amplificaban el sentido de la palabra escrita y que no dejaban margen a la duda: las denuncias contra la represión y las guerras se presentaban como un basamento para organizar una lucha antifascista desde el universo de las izquierdas. En este sentido, las tres portadas de esta publicación podrían pensarse como una suerte de condensación de su programa pues, así como en su primera tapa se muestra una avioneta de guerra y su piloto como denuncia de la primera postguerra (y, por qué no, el advenimiento de una posible segunda guerra mundial), en la segunda el retrato de Henri Barbusse ocupaba toda la plana para reforzar los subsiguientes homenajes en su interior que lo situaban como modelo de intelectual comprometido a seguir. La tercera portada, ilustrada con una caricatura de Hitler y Mussolini que —arriba de un recuadro que recuerda el aniversario de la Revolución Rusa (7 de noviembre, 1917-1935)— se esfuerzan mancomunadamente por derribar la hoz y el martillo, símbolo de la unión de los trabajadores y el ideario comunista, complementaba el tríptico (Figura 1). 
FIGURA 1

Rumbo, año I, n 3, Buenos Aires, noviembre 1935

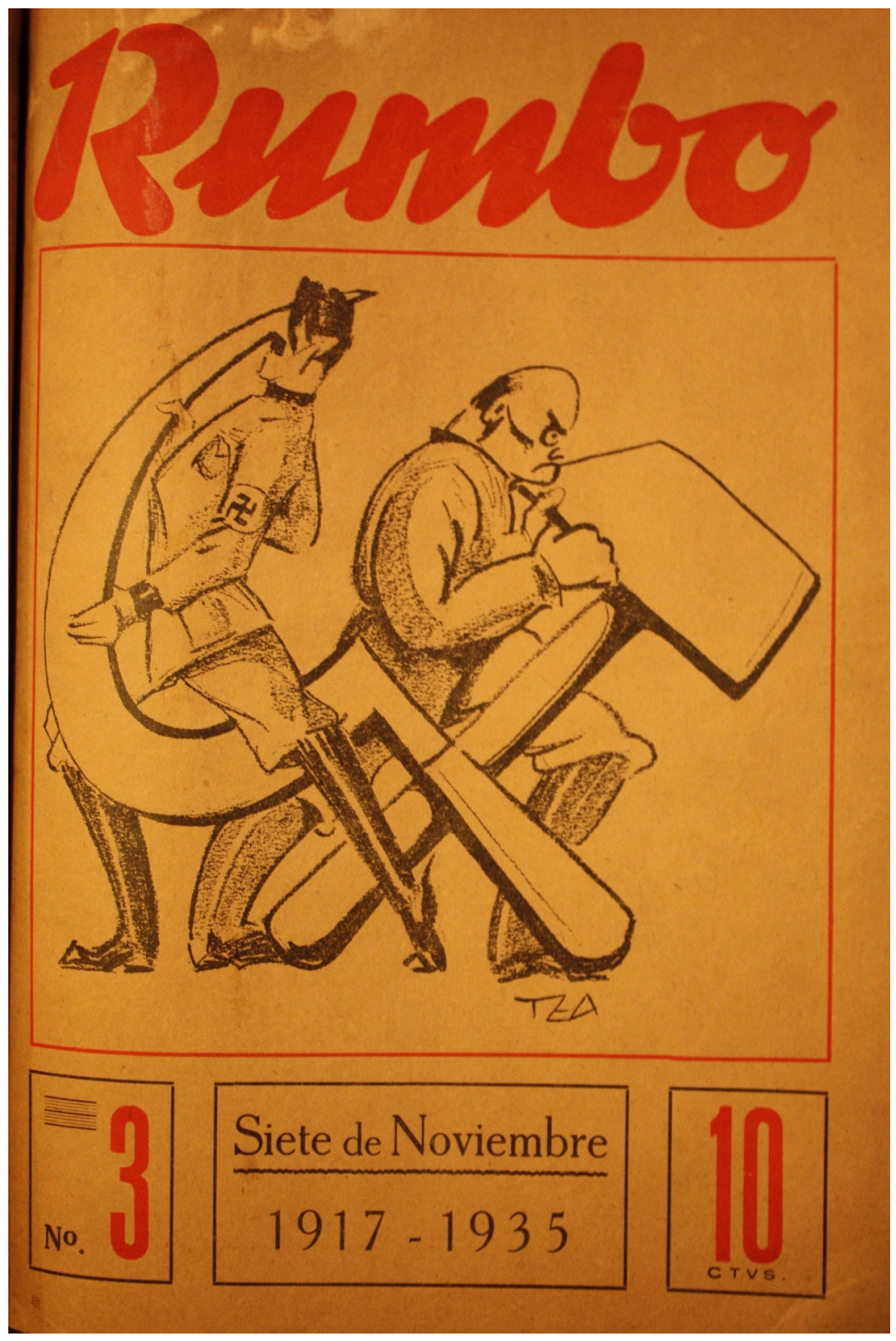

Colección CeDInDI

Estas imágenes, que buscaban interpelar y movilizar al lector, también reforzaban la idea de Rumbo como una publicación de "este siglo y de este año". Concretamente, el año 1935 fue atravesado por el clima generado por el discurso de Georgi Dimitrov en el VII Congreso de la Internacional Comunista, que proclamaba la necesidad de constituir Frentes Únicos y Populares para enfrentar no sólo a Mussolini y a Hitler, sino también a cualquier posible nuevo representante del fascismo (Dimitrov, 1984, pp.153-220). De esta manera, la puesta en marcha de la estrategia frentista, aprobada rápidamente por el Partido Comunista Argentino (PCA), abría una nueva etapa en la relación del partido con los escritores y los artistas, que permitiría saldar momentáneamente las profundas tensiones del período previo, caracterizado por la línea partidaria de la lucha "clase contra clase", una estrategia obrerista que obturaba la participación de los intelectuales en el partido, sospechados de "pequeñoburgueses". 
A su vez, el el 28 de junio de 1935, apenas tres días después de celebrarse el mencionado congreso internacional, se había sido fundada en la ciudad de Buenos Aires la AIAPE (Cane, 1997; Bisso y Celentano, 2006; Pasolini, 2013). Esta agrupación de intelectuales —inspirada en el modelo francés del Comité de Vigilance des Intellectuels Antifascistes (Pasolini 2017) y presidida en sus inicios por Aníbal Ponce- ${ }^{3}$ ocupó un lugar central en la configuración de una red de militancia antifascista en el ámbito de la cultura, logrando aglutinar a un amplio conjunto de intelectuales, escritores y artistas vinculados a diferentes familias políticas, aunque pronto se hizo notar en esa formación el predominio de las izquierdas que se trasluce en la pertenencia ideológica o partidaria de la mayoría de sus afiliados como, por ejemplo, Yunque, Córdova Iturburu, Héctor Agosti, Raúl Larra, Emilio Troise, Elías Castelnuovo, Alberto Gerchunoff, Nydia Lamarque, Liborio Justo, César Tiempo, Raúl González Tuñón, Rodolfo Puiggrós, José Portogalo, Deodoro Roca, Leonardo Estarico, Alfredo Varela, Sergio Bagú, Dardo Cúneo, Lino Enea Spilimbergo, Cecilia Marcovich, Pompeyo Audivert, Antonio Berni, Demetrio Urruchúa, Gregorio Bermann, Bernardo Edelman y Carlos Ruiz Daudet, entre tantos otros. No obstante, como se ha señalado en la introducción, la AIAPE no contó con un órgano oficial hasta enero de 1936, motivo por el cual su prédica se hizo oír a través de otras publicaciones, entre ellas y de forma destacada en Rumbo que también albergaba a muchos de sus integrantes. De hecho, por medio de Rumbo se solicitó, con cuadros destacados, a que los profesionales, artistas plásticos, escritores y periodistas se inscriban a la AIAPE; además se evidencia el uso de la protesta como arma de combate.

La protesta, rasgo fundamental de la movilización de los intelectuales, ocupó un lugar central, pues la publicación del primer número de Rumbo coincidió con la condena al poeta Raúl González Tuñón. Recuérdese que, con la publicación del poema "Las Brigadas de choque", la revista Contra sufrió la inmediata censura mientras que González Tuñón fue acusado y procesado judicialmente bajo el cargo de "incitar a la rebelión”. Exactamente dos años después, en agosto de 1935, fue condenado a dos años de prisión y las protestas de los intelectuales no se hicieron esperar. La AIAPE se pronunció a través de Rumbo, en donde se reprodujo un comunicado emitido y aprobado por la agrupación antifascista el 7 de agosto, en su primera asamblea fundacional. Allí, se resolvió "protestar por la restricción de la libertad de pensamiento que significan 'procesos de tendencia"” y expresar su simpatía y solidaridad al escritor condenado (Ponce y Puiggrós, 1935, p.5). Lo interesante es que con el objetivo de potenciar dicha protesta — firmada por Aníbal Ponce y Rodolfo Puiggrós, presidente y secretario de la AIAPE respectivamente-, esta era complementada por una caricatura realizada por Pastor Sigfredo (Figura 2).

\section{FIGURA 2}

Rumbo, año I, n 1, Buenos Aires, septiembre 1935.

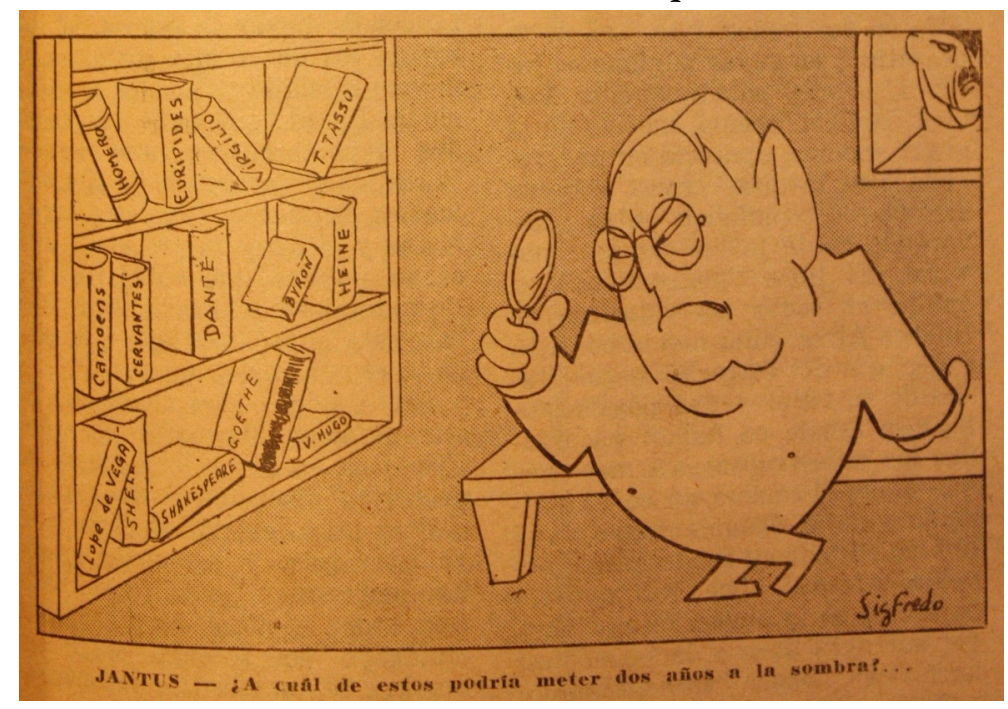

Colección CeDInDI 
En ella, el principal responsable del procesamiento de González Tuñón, el juez federal Miguel Jantus, era representado con una lupa en la mano que apunta hacia una biblioteca mientras se pregunta: " ¿A cuál de estos podría meter dos años a la sombra?...”. Por medio de la ironía, el artista gráfico impugnaba la condena dictada al poeta argentino al situar en aquella biblioteca a un conjunto de nombres representativos de la cultura universal como Homero, Dante, Cervantes, Shakespeare y Víctor Hugo. En un segundo plano de la escena, se observa un cuadro de Adolf Hitler que opera como un modo de articular los fascismos provenientes del otro lado del Atlántico en un entramado más amplio, que incorpora a este fenómeno en la esfera local. De acuerdo con la interpretación dimitroviana que se imponía por entonces, el fascismo era percibido no sólo como la forma última que asumía la dictadura de la clase capitalista sino también como el enemigo de la inteligencia y de la cultura; una interpretación que reforzaba su carácter de fenómeno internacional y su posible variante "criolla" (Bisso, 2000). En este sentido, en su declaración programática, la AIAPE realizaba un diagnóstico de la situación actual que no dejaba alternativa alguna:

\begin{abstract}
La humanidad vive una hora de trascendente disyuntiva. Dos caminos se abren sobre ella: continuación del progreso milenario, retorno a la barbarie de edades superadas. Ha llegado el momento en que no basta crear cultura. Es menester aprestarse a defenderla [...] En la tierra donde el temor a la hoguera impuso ayer a Galileo la negación del movimiento del planeta, hoy el fascismo, adueñado del poder, quiere, además de la hegemonía política de la nación, la hegemonía de las expresiones de cultura. Y para aquellos que se niegan a corear con sus voces las loas mercenarias, el estado reserva la cárcel, las torturas, el destierro, la destitución (AIAPE, 1935).
\end{abstract}

Estas apreciaciones se profundizaban con la censura sufrida por otros intelectuales y el secuestro de sus publicaciones, lo que impulsó el trazado de paralelismos con la quema de libros llevada a cabo por la Alemania nazi en mayo de 1933, pues cabe recordar que la censura sufrida por Raúl González Tuñón no fue la única. Por entonces, el juez Jantus también había ordenado a la Sección Especial de Represión del Comunismo, dependiente de la Policía de la Capital, el arresto de Héctor P. Agosti como responsable del diario Bandera Roja, publicación vinculada al PCA. Al igual que en el caso de González Tuñón, se lo acusaba de “incitar a la rebelión" y de desacato a la autoridad. Otro caso representativo de este tipo de procesos judiciales fue el de José Portogalo, considerado un "hombre peligroso" por la publicación del poemario Tumulto, en noviembre de 1935, y que involucró a Demetrio Urruchúa, convocado a comparecer ante tribunales por su "complicidad" como ilustrador de dicha obra. Si bien este poemario había obtenido ese mismo año el tercer premio en el Concurso Municipal de Literatura de Buenos Aires, al conocerse su contenido el intendente Mariano de Vedia y Mitre ordenó su prohibición y el secuestro de los ejemplares ya distribuidos e inició una causa judicial por "ultraje al pudor" (Ponce, 1936; Alzari, 2012). A su vez, Jantus instruyó una causa paralela para privar a Portogalo de la ciudadanía argentina y posteriormente proceso similar fue padecido por el escritor Elías Castelnuovo, acusado de "indeseable y peligroso" (Marigne, 1936). A partir de estos casos, que evidenciaban los límites de la libertad de expresión y las represalias frente al "temor comunista”, se llevaron a cabo como respuesta enconadas denuncias que llegaron al Honorable Cámara del Diputados del Congreso de la Nación (López Cantera, 2014). ${ }^{4}$

Siguiendo con la protesta de la AIAPE publicada en Rumbo, en la página siguiente, una larga nota de César Tiempo (seudónimo de Israel Zeilin), también socio de la agrupación, refiere nuevamente a la condena dictada a González Tuñón a través de un título - “¿Por qué se encuentra en libertad el director de la Biblioteca Nacional?" - que constituía una suerte de contradenuncia a la realizada por el juez Jantus. Por entonces, el director de dicha institución era el escritor católico Gustavo Martínez Zuviría que bajo el seudónimo literario Hugo Wast había publicado recientemente El kahal y Oro, dos obras de contenido antisemita que lograron una gran circulación y el éxito comercial gracias a su recepción en los círculos católicos y nacionalistas (Lvovich 1999). No obstante, los sectores afines a los valores democráticos y humanistas repudiaron tanto la difusión de sus contenidos antisemitas como su desprecio a la Constitución Nacional, de allí que Cesar Tiempo se interroga: “`cómo es que el señor Fiscal que formuló la acusación contra el poeta leyó la furtiva revista donde apareciera el cálido poema de marras y no vio los dos tomos detonantes 
que se exhiben en todos los escaparates de librería y cuyos capítulos fueron anticipados o reproducidos en buena cantidad de diarios del país?" (Tiempo, 1935). Con esta estrategia de preguntas retóricas, Cesar Tiempo procuraba exponer no sólo la afinidad de Martínez Zuviría con el nazismo que traduciría en sus páginas "los odios cavernarios que sustentaban la política sadista del tercer Reich", sino también la realidad argentina de un contexto caracterizado por el fraude electoral, la corrupción de los funcionarios públicos y la persecución política padecida por una importante cantidad de escritores que no podían escapar a la infiltración de la "amenaza nazifascista". 5

Por último, cabe señalar que este tipo de casos judiciales había trascendido el ámbito local al ser difundidos en el Congreso Internacional de Escritores para la Defensa de la Cultura, realizado en junio de 1935 en París, y en el que participó González Tuñón como socio de la AIAPE. Por ejemplo, en la revista Izquierda. Acción y Critica Socialista fue reproducida otra protesta que expresaba:

Escritores de diversos países y variadas creencias e ideas políticas protestamos, en nombre de la dignidad del pensamiento y de la libertad de expresión, contra la política ejercida por ciertos gobiernos latino-americanos que, como el de Argentina, sostiene una Sección Especial de Policía dedicada a perseguir a escritores y artistas y a intentar contra ellos procesos desprovistos de todo fundamento (1935). ${ }^{6}$

Ahora bien, en simultáneo con estas protestas se instalaba en Rumbo otro debate: el de la función del arte, introducido por una serie de misceláneas que se complementaban con diversas notas y por medio de frases como la de José Martí, de quien se citaba: "Los versos no se han de hacer para decir que se está contento o triste, sino para ser útil al mundo”. De esta manera, a partir de un acto represivo sufrido por González Tuñón y su respuesta en las páginas de Rumbo se evidenciaba el poder que poseían la pluma y el pincel como armas de combate al tiempo que se insistía en la necesidad de la organización de los intelectuales.

\section{ENTRE EL ARTE PRoletario y LA DEFENSA DE LA CULTURA}

Con el objetivo de promover un arte "comprometido" con la actualidad, el colectivo de Rumbo expuso una serie de representaciones y debates en torno al papel de los intelectuales y la función social del arte, por medio de los cuales se revela la tensión presente en un momento de transición, que se tradujo en una problemática convivencia entre el "arte proletario", promovido en el período de "clase contra clase", y la apertura a todas las tendencias artísticas fomentado por la nueva estrategia frentista, cuyo objetivo primordial era la "defensa de la cultura". La coexistencia en la publicación de poesías proletarias, la publicitada creación de la Agrupación de Jóvenes Escritores (AJE), la encuesta sobre "arte proletario” y el número homenaje a Henri Barbusse, evidencian esa tensión.

El término "arte proletario" circulaba en el ámbito local como resultado de las lecturas de la obra de Alexander Bogdanov (1979), quien postulaba que desde un punto de vista proletario el artista debía convertirse en su "portavoz estético". En este sentido, podían devenir en "artistas proletarios" aquellos artistas dispuestos a difundir una obra al servicio de la clase obrera, lo que demandaba, a su vez, una claridad en el mensaje basado en un optimismo que incentivara la organización y la lucha obrera a favor de la causa soviética. En sintonía con estos postulados, en el primer número de Rumbo, y precisamente con el título de "Poesía proletaria", se publican a doble página dos poesías de Juan M. Prieto - "Usina” y "Grito" - en las que se manifiesta el papel de la clase trabajadora en la construcción de una sociedad futura y de la ideología comunista como su cimiento; una posición morigerada en las siguientes páginas con la declaración de la AJE. Esta agrupación que poco tiempo después se articularía con la AIAPE, llamaba a la "defensa de la cultura" sin bregar abiertamente por un "arte proletario" más allá de sus probadas simpatías (Larra, 1986, p.35). Pero en donde emergen con mayor claridad las divergencias señaladas es en la encuesta llevada a cabo a lo largo de los tres números de la revista y que constaba de seis preguntas, entre las que se destaca la última - “Cree Ud. que nuestra época el trabajador intelectual comunista puede hacer obra constructiva y profunda? -, 
pues como uno de los encuestados advierte "llama la atención porque se formula con toda claridad". ${ }^{7}$ Esta observación del nacionalista Ramón Doll, que no escapa a la ironía, se articula con todas sus valoraciones opuestas a cualquier participación del intelectual en la lucha política. Su respuesta con sorna ejemplifica:

Imagínense Uds. a un Aníbal Ponce conduciendo masas a la revolución. Confiesen que la visión los haría reír a carcajadas. Con cuatro gritos de un sargento "meneur" perdería los lentes, su calva enrojecería y el espectáculo sería penoso. Y sin embargo Ponce es sin duda un intelectual destacado (Doll, 1935, p.15).

Esta opinión que incluye el uso de un término leboniano (proveniente del célebre ensayo La psicología de las masas, de Gustave Lebon) se complementa con el cuestionamiento directo al uso de epítetos como "arte proletario" y de cualquier accionar comunista. Evidentemente, la palabra de Doll, que dio apertura a la encuesta, fue elegida de un modo intencionado para mostrar una variedad de posicionamientos y hacer alarde de la pluralidad de expresiones que impulsaba la revista. Sin embargo, la opinión del escritor católico que, vale recordar, había celebrado la aparición de los libros de Martínez Zuviría (Lvovich, 1999, p.149), tuvo escasa compañía en las páginas de Rumbo. ${ }^{8}$ Por el contrario, las respuestas de Vicente Barbieri, Enrique S. Portugal, López Azcona (obrero pintor), Elías Castelnuovo y el aprista Luis Alberto Sánchez, optaron, con matices, por un arte al servicio de la lucha social. Para dar un ejemplo que se sitúa en el otro extremo de Doll, Castelnuovo se pronuncia terminantemente del lado de la lucha social, pues con una visión proveniente de un marxismo determinista expresa: "Preguntar si un artista 'debe' o no participar en las luchas de un tiempo es como preguntar si 'debe' o no comer cuando tiene hambre [...] No se lucha por luchar. Ni se lucha por una imposición del espíritu. Se lucha por una imposición de la economía (Castelnuovo, 1935, p.11)”. Enseguida Castelnuovo declama la necesidad de desarrollar un "arte proletario" en Argentina y concluye que para alcanzarlo, y siguiendo la premisa de Marx ("Trabajadores del mundo, uníos"), habría que lograr la unión de los intelectuales. Esta visión se corresponde con el viraje estético e ideológico que se produjo en la producción literaria de Castelnuovo a raíz de su viaje a la Unión Soviética (Saítta, 2008, p.99) y que quedó plasmado en el El arte y las masas, publicado precisamente en 1935 y publicitado en las páginas de Rumbo.

Por último, la respuesta de Sánchez, que no desiste de tomar una posición a favor de la acción de los intelectuales, se distancia del llamado "arte proletario" producto del quehacer del intelectual comunista, pues:

No veo porqué el "intelectual comunista" - y sólo él- sea el único que se pregunte si puede hacer obra de arte durable. A menos que los errores de la Tercera Internacional, en su línea política e intelectual, le hayan empujado a la duda. Todo intelectual revolucionario está en aptitud de crear obra duradera. Nadie le pregunta a Malraux si es comunista o no. Nos interesa su aliento prácticamente humano. Nosotros los apristas escritores - cosa distinta a los escritores apristas- tenemos la seguridad de que estamos haciendo una obra fecunda y duradera, escuchando los reclamos de la vida, sin atenernos a fríos esquemas mentales, a prioris que enfrían y falsifican la expresión vital (1935, p.13).

Esta opinión de Sánchez se complementa y articula con algunas de las valoraciones aparecidas en el número homenaje dedicado a Henri Barbusse en el segundo número de Rumbo, en el que se intercalan elogios al escritor, poesías, ilustraciones, recuerdos personales como el encuentro entre Nydia Lamarque y el escritor francés en el Congreso de Mujeres contra la Guerra y el Fascismo, entre otras intervenciones. Entre todas estas notas se destaca, por el espacio que ocupan en la revista y por la trascendencia que alcanzó el evento, la reproducción de los discursos de Isidro Odena y Cora Ratto pronunciados en el "Funeral cívico" realizado el 21 de septiembre en el Teatro Corrientes con el auspicio y la organización de la AIAPE. ${ }^{9}$

Los dos discursos reproducidos por Rumbo dejan en evidencia la tensión entre el clasismo residual y el viraje hacia el antifascismo que caracterizó a la breve experiencia de esta publicación, pues mientras que Odena enfatiza el viaje de Barbusse a la Unión Soviética y su condición de militante comunista (1935, p.3), Ratto, como representante de la Agrupación Femenina Antiguerrera, exalta el reconocimiento de este "apóstol de la paz" hacia las mujeres que se involucraron en la lucha antiguerrera:

Necesitamos ahora conseguir la fuerza de su pasión por la paz, pues somos débiles; apoyarnos, pues somos falibles, en el ejemplo de su valiente lucha. Con esas armas cumpliremos la difícil tarea de atraer al camino de amor universal que él 
iniciara a todos los hombres. Es el único verdadero homenaje que podemos ofrecer a su memoria -como él lo quiso- por encima de todos los credos políticos y religiosos, emprender unidos una intensa campaña por crear una verdadera conciencia antiguerrera (1935, p.2).

De esta manera, las palabras de Ratto sobre Barbusse se sumaban a las de otros oradores del funeral cívico como Aníbal Ponce y Alberto Gerchunoff, reproducidas posteriormente en Unidad. Por la Defensa de la Cultura (primer órgano de la AIAPE) que hicieron de esta figura, al igual que de la de Romain Rolland, una suerte de profeta laico cuyo itinerario resumía de modo paradigmático el abandono de la conciencia burguesa en favor de un nuevo compromiso intelectual, condición que lo situaba como uno de los "padres del antifascismo" (Pasolini, 2013, pp.93-98).

Por último, cabe destacar que la presencia de Barbusse también se hizo visible en las páginas de Rumbo en el esfuerzo por establecer redes intelectuales entre el universo antifascista francés y el Río de la Plata. Luego del fallecimiento del escritor francés, la revista dirigida por Barbusse, Monde. Hebdomadaire d'information littéraire, artistique, scientifique, économique et sociale, dejaría de existir. El número del 12 de septiembre anunciaba una inevitable reorganización de la redacción debido a la muerte de su director y al siguiente número, el 26 de septiembre, informaba a sus lectores que, de modo unánime, la redacción había decidido continuar con la labor política e intelectual trazada por el semanario. Sin embargo, el 10 de octubre de 1935, a pesar de un artículo que afirmaba nuevamente el plan de continuar con el movimiento de los Amis de Monde, Monde salió por última vez a las calles de París (Devés, 2017, p.144). Esa declaración de su número final también podría explicar el origen de la edición de Monde que vio la luz en Montevideo, Uruguay, a partir de la primera quincena de febrero de 1936. Pues, como anticipó y publicitó en reiteradas ocasiones Rumbo, la revista francesa ahora comenzaría a publicarse en español, bajo la dirección de Pedro Ceruti Crosa. En efecto, el periódico homónimo retomó la numeración de la revista parisina y comenzó a editarse desde Montevideo. La nota editorial del primer número de esta nueva etapa de Monde evocaba, a propósito del jubileo de Romain Rolland, a este escritor junto con la figura de Barbusse, sintetizando ambos la unión de la lucha "por la cultura, en contra la guerra, contra el fascismo, por la justicia social” (1936, p.1); una representación, como se señaló, compartida y fomentada por el colectivo de Rumbo. ${ }^{10}$

\section{Palabras finales}

El abordaje de Rumbo posibilitó incorporar a esta revista poco conocida dentro de la trama antifascista local, pero sobre todo corroboró, una vez más, la potencialidad que ofrece el estudio de las publicaciones culturales para abordar problemas más amplios de la sociedad y la cultura. En este caso, Rumbo se constituye como un eslabón, entre otros, para promover "la defensa la cultura" en un período signado por la polarización política "fascismo-antifascismo" y la transición de estrategias dictaminada por la Internacional Comunista. En este sentido, dio lugar a colaboraciones y pronunciamientos de una de las agrupaciones de intelectuales más destacadas por entonces: la AIAPE, que aún no contaba con sus propios órganos oficiales. Asimismo, en ese momento transicional, Rumbo se presenta como un soporte privilegiado para analizar, por un lado, las batallas intelectuales que se profundizaban en dicho contexto, como pudo observarse por ejemplo por medio de las respuestas y protestas que surgieron a partir del caso González Tuñón y, por el otro, los debates estético-políticos que manifestaban la persistencia de un clasismo residual entre la reivindicación de un "arte proletario" y la apertura a todas las tendencias artísticas fomentadas por la nueva estrategia frentista.

Además, gracias a los aportes ofrecidos por los estudios dedicados a la cultura visual, es posible observar cómo el lugar asignado a las imágenes en la diagramación de Rumbo son parte de las diversas estrategias de intervención a las que apeló su colectivo editor para instalar debates, amplificar los mensajes y reforzar las relaciones entre los sucesos y referentes europeos en el ámbito nacional. Por último, esta dimensión trasnacional, que fue una característica del movimiento antifascista, se consolidó con el establecimiento de 
una red de publicaciones entre ambos continentes, como la establecida entre Monde y el Río de la Plata, muy publicitada por Rumbo.

\section{ReFERENCIAS}

AAVV. (1935). "Declaración del Congreso Internacional de Escritores para la Defensa de la Cultura", Izquierda. Acción y Crítica Socialista, año I, (6), p. 38.

AIAPE. Sección Buenos Aires y Rosario (1935). "Declaración programática: A los intelectuales de Latino-América", s/p. Archivo Fundación Espigas.

AIAPE. (1935). Rumbo, año I, (1), septiembre, p. 5.

Altamirano, C. (2006), Intelectuales. Notas de investigación. Bogotá: Norma.

Alzari, A. (2012). Introducción a José Portogalo, Tumulto. Rosario: Serapis, 2012 [Buenos Aires, Imán, 1935], s/p.

Bisso, A. (2000). El antifascismo latinoamericano: usos locales y continentales de un discurso europeo. Asian Journal of Latin American Studies, Seul, vol. 3, pp. 91 - 116

Bisso, A. (2007). El antifascismo argentino. Selección documental y estudio preliminar. Buenos Aires: CeDInCI Editores / Buenos Libros, pp. 15-97.

Bisso, A. y Celentano, A. (2006). La lucha antifascista de la Agrupación de Intelectuales, Artistas, Periodistas y Escritores (AIAPE) (1935-1943). En H. Biagini y A. Roig, El pensamiento alternativo en la Argentina del siglo XX. Tomo II, Obrerismo, vanguardia, justicia social (1930-1960). Buenos Aires: Biblos, pp. 235-266.

Bogdanov, A. (1979). El arte y la cultura proletaria. Madrid: Comunicación-Alberto Corazón editor.

Cane, J. (1997). "Unity for the Defense of Culture": The A.I.A.P.E. and the Cultural Politics of Argentine Antifascism, 1935-1943. The Hispanic American Historical Review, vol. 77, (3), Duke University Press, pp. 443-482.

Castelnuovo, E. (1935). Encuesta, año I,( 3), Buenos Aires, noviembre, p. 11.

Devés, M. (2017). Arte y antifascismo en la revista Monde (1928-1935). Políticas de la Memoria. Anuario de investigación del CeDInCI, (17), CeDInCI-UNSAM, pp. 180-193.

Dimitrov, G. (1984). La ofensiva del fascismo y las tareas de la Internacional Comunista en la lucha por la unidad de la clase obrera contra el fascismo. En AA.VV., Fascismo, democracia y frentepopular. VII Congreso de la Internacional Comunista. México DF: Siglo XXI, pp. 153-220.

Doll, R. (1935). Encuesta. Rumbo, año I, (1), p. 15.

Dosse, F. (2007). La marcha de las ideas. Historia de los intelectuales, historia intelectual. Valencia: Universidad de Valencia.

Greco, M. (2015). De la vanguardia estética a la vanguardia política (Argentina, 1930-1931). Badebec. Revista del Centro de Estudios de Teoría y Critica Literaria, vol. 5, (9), pp. 213-242.

Larra, R. (1986). Con pelos y señales. Buenos Aires: Futuro.

López Cantera, M. (2014). Criminalizar al rojo. La represión al movimiento obrero en los informes de 1934 sobre la Sección Especial. ARCHIVOS de historia del movimiento obrero y la izquierda, (4), pp. 101-122.

Lvovich, D. (1999). Una mirada sobre el antisemitismo de la década de 1930: El Kahal-Oro de Hugo Wast y sus comentaristas. Cuadernos del CISH, año 4, (5), pp. 131-150.

Marigne, J. (1936). Defendamos a Castelnuovo. Símbolo. Revista abierta a todas las tendencias modernas del espiritu, año $I I,(7)$, p. 18.

Monde (1936). Nuestro homenaje a Romain Roland en su jubileo. Monde. Revista internacional fundada por Henri Barbusse, (1/354), pp. 1-2.

Nallin, J. (2006). En torno a los orígenes del antiperonismo: la Unión Democrática frente a la instauración del aguinaldo (1945-46). En M. García Sebastiani (ed.), Fascismo y antifascismo. Peronismo y antiperonismo. Conflictos políticos e ideológicos en la Argentina (1930-1955). Madrid: Iberoamericana, pp. 77-105.

Odena, I. (1935). Discurso de Isidro Odena. Rumbo, año I, (2), pp. 3-4. 
Pasolini, R. (2013). Los marxistas liberales. Antifascismo y cultura comunista en la Argentina del siglo XX. Buenos Aires: Sudamericana, pp. 84-98.

Pasolini, R. (2013). Entre antifascismo y comunismo: Aníbal Ponce como ícono de una generación intelectual. Iberoamericana, XIII, (52), pp. 83-97.

Pasolini, R. (2016-2017). El Comité de Vigilance des Intellectuels Antifascistes, la prensa periódica y "L'esprit des années trente". Politicas de la Memoria. Anuario de investigación del CeDInCI, (17), pp. 122-133.

Ponce, A. (1936). El primer año de la AIAPE. Dialéctica, año I, (6), pp. 329-334.

Ponce, A.y Puiggrós, R. (1935). Protesta. Rumbo, año I, (1), septiembre, p. 5.

Portugal, E. (1935). Encuesta. Rumbo, año I, (2), octubre, p. 12.

Ratto, C. (1935). Discurso de Cora Ratto. Rumbo, año I, (2), pp. 2-3.

Rumbo (1935). Encuesta. Rumbo, año I, (1), p. 15.

Saítta, S. (2005). Polémicas ideológicas, debates literarios en Contra. La revista de los franco-tiradores, Estudio Preliminar a Contra, la revista de los franco-tiradores. Buenos Aires: UNQUI, pp. 13-33.

Saítta, S. (2008). Elías Castelnuovo, entre el espanto y la ternura. En Á. F. Bolaños, G. Cleary Nichols y S. Sosnowski (ed.), Literatura, politica y sociedad: construcciones de sentido en la Hispanoamérica contemporánea. Homenaje a Andrés Avellaneda. Universidad de Pittburg.

Sánchez, L. A. (1935). Encuesta. Rumbo, año I, (1), p. 13.

Sin firma (1935). Rumbo. Rumbo, año I, (1), septiembre, p. 1 .

Tarcus, H. (2009). Aníbal Ponce en el espejo de Romain Rolland. Estudio preliminar a A. Ponce, Humanismo Burgués y humanismo proletario. Buenos Aires: Capital Intelectual, pp. 7-25.

Tiempo, C. (1935). ¿Por qué se encuentra en libertad el director de la Biblioteca Nacional?. Rumbo, año I, (1), septiembre, p. 6.

Traverso, E. (2003). Los intelectuales y el antifascismo. Por una historización crítica. Acta Poética, vol. 24, (2), Instituto de Investigaciones Filológicas, UNAM, Coyacán, pp. 51- 72.

\section{Notas}

1 El presente artículo fue financiado por la Agencia Nacional de Promoción Científica y Tecnológica. Proyecto PICT 2016-1226: "Literatura, revistas culturales y prensa en la Argentina (1880-1950)".

2 Publicitada en las contratapas de Rumbo por medio de recuadros se destacaba que: "Publicaciones Atlas editará libros de los más representativos escritores de la Argentina y América”. Lo cierto es que sólo se publicó 13 años, de Álvaro Yunque y anunció la próxima aparición de Muchedumbres, de Nydia Lamarque sin que este claro que se haya impreso.

3 Luego de ser exonerado de su cargo como profesor y su partida a México, la presidencia de Aníbal Ponce (1935-1936) fue seguida por las de Emilio Troise (1936-1942) y Gregorio Bermann (1942-1943). Ponce, como el más destacado discípulo de uno de los intelectuales más influyentes de aquellos años, José Ingenieros, resulta por demás interesante como figura aglutinadora de la intelectualidad de izquierda hasta su temprana muerte en 1938 (Tarcus 2009; Pasolini 2013).

4 Mercedes López Cantera (2014) analiza Bajo el terror de Justo, un folleto publicado por el Socorro Rojo Internacional (SRI) que ofrece un detallado informe y balance sobre la aplicación de la ley de residencia (4144), las torturas y encarcelamientos padecidos por el movimiento obrero desde el gobierno de Uriburu y continuado por Justo.

5 En el siguiente número de Rumbo, una sección dedicada a las novedades bibliográficas se añadía que: "Martínez Zuviría podrá ser un convencido propagandista católico o un fogoso panfletario antisemita; pero en sus dos recientes novelas o alegatos- demuestra evidentemente que no es artista". "Libros", Rumbo, octubre 1935, p.15. Esta apreciación pone el foco en la necesidad de articular el arte con la política sin desdeñar la calidad artística, una cualidad que, se sostiene, ni siquiera podría atribuirse a Martínez Zuviría.

6 Firman esta declaración: Michael Gold, Waldo Frank (Estados Unidos); André Gide; Henri Barbusse; André Malraux; Tristan Tzara; Luis Aragón; Jean Richard Bloch; Vaillant Couturier; Jean Cassou; Leon Mousinac; Jean Guehenno (Francia); Heinrich Mann; Ann Seguers; H. Hertz (Alemania); Julio Álvarez del Vayo; Rafael Dieste; Serrano Plaja; Carranque de Ríos; Manuel Benavídez; Juan Piqueras (España); César Vallejo (Perú); L. Stoyanoff; Sokolow (Bulgaria); A. Goiger (China); N. S. Cey (Polonia); S. Th. Dudow (Rumania); Enrique Cornojo; Herminia del Portal (Cuba); Siao (China); W. C. Cayton ("delegado negro" [sic]). 
7 El resto del cuestionario preguntaba: “1) ¿Qué posición debe adoptar el trabajador intelectual frente a la crisis que agita a la sociedad capitalista? ¿Debe participar en ella o permanecer alejado?, 2) ¿Si Ud. cree que debe participar en ella, en qué forma puede hacer efectiva esa participación?, 3) ¿Cree Ud. en la existencia del llamado "arte puro", o es su opinión que el arte debe ser influenciado por las preocupaciones de la época y participar en sus luchas?, 4) ¿Cree Ud. que debe hacerse arte en un momento dramático como el que vivimos?, 5) ¿Debe el arte servir de propaganda?” (Rumbo, septiembre 1935, p.15)

8 De hecho, la voz de Doll le valió la respuesta de Enrique S. Portugal, quien reprochó a Yunque su presencia: "He leído la encuesta que promueve RUMBO y la brillante respuesta del fasciocanalla Ramón Doll; de ese insignificante cagatinta Doll, padre congénito y putativo de 'Democracia mal menor', y cuatro sandeces más que andan por ahí envueltas a manera de rollos de papel higiénico" (Portugal, 1935, p.12).

9 También tomaron la palabra en este acto-homenaje Aníbal Ponce, Alberto Gerchunof, Rodolfo Aráoz Alfaro, M. P. Alberti y Emilio Troise, aunque sus discursos no fueron reproducidos por Rumbo.

10 Lamentablemente, esta fue una experiencia fugaz y sólo llegaron a publicarse seis números, desde febrero a julio de 1936, y un Boletín de Monde. Semanario internacional. Homenaje de "Amigos de Monde" de Montevideo que contenía la traducción de uno de los últimos números publicados en París (el número 350) dedicado a homenajear a su fundador luego de su fallecimiento (“iHenri Barbusse ha muerto!”). 